\title{
EFEITOS DA INTERAÇÃO GENÓTIPO X AMBIENTE NO CICLO E NA COLORAÇÃO DO TEGUMENTO DOS GRÃOS DO FEIJOEIRO COMUM ${ }^{(1)}$
}

\author{
NERINÉIA DALFOLLO RIBEIRO(2); EVANDRO JOST $^{(3)}$; ALBERTO CARGNELUTTI FILHO $^{(4)}$
}

\begin{abstract}
RESUMO
O objetivo deste trabalho foi estudar os efeitos da interação genótipo $\mathrm{x}$ ambiente, visando identificar cultivares de feijão com estabilidade para a coloração do tegumento dos grãos e para o ciclo na região da Depressão Central do Rio Grande do Sul. Seis experimentos foram instalados nos anos agrícolas 2000/ 01, 2001/02 e 2002/03, nos cultivos de safra (semeadura em setembro-outubro) e de safrinha (semeadura em janeiro-fevereiro), em área do Departamento de Fitotecnia da Universidade Federal de Santa Maria. O delineamento experimental utilizado foi o de blocos ao acaso, com três repetições, e os tratamentos consistiram de 16 cultivares de feijão. Os resultados evidenciaram que a coloração do tegumento dos grãos em cultivares de feijoeiro comum do grupo comercial carioca é influenciada pelo ambiente. As cultivares Carioca, Diamante Negro, TPS Nobre e TPS Bionobre apresentam alta previsibilidade para obter grãos de feijão de cor de tegumento adequados às exigências do mercado consumidor. Nenhuma cultivar de feijão apresentou estabilidade para ciclo.
\end{abstract}

Palavras-chave: Phaseolus vulgaris, estabilidade, cor dos grãos, maturação.

\section{ABSTRACT \\ GENOTYPE X ENVIRONMENT INTERACTION EFECTS IN CYCLE GRAIN IN COMMON TEGUMENT COLOUR AND CYCLE IN BEAN CULTIVARS}

The objective this work was to assess the effects of genotype $x$ environment interaction in order to identify bean cultivars with stability for grain tegument colour and cycle in the central depression region of Rio Grande do Sul in order to guide breeding programs. Six experiments, with 16 common bean cultivars were conducted during the 2000/01, 2001/02 and 2002/03 growing season and sowing was carried out on Set/Out (Crop 1) and on Jan/Fev (Crop 2) in experimental fields of the Plant Science Department of the Santa Maria Federal University. Complete randomized blocks with three replications as used. Results showed that colour of grain tegument in carioca beans was influenciated by the environment. 'Carioca', 'Diamante Negro', 'TPS Nobre' and 'TPS Bionobre' showed high predictability for production of bean grains with tegument colour with acceptable preference by consumers. Nothing bean cultivar showed stability for cicle.

Key words: Phaseolus vulgaris, stability, grain colour, maturity.

$\left({ }^{1}\right)$ Recebido para publicação em 5 de abril e aceito em 5 de julho de 2004.

( $\left.{ }^{2}\right)$ Departamento de Fitotecnia, Centro de Ciências Rurais, Universidade Federal de Santa Maria (UFSM), 97105-900 Santa Maria (RS). E-mail: neiadr@smail.ufsm.br

(3) Aluno do Curso de Agronomia da UFSM. Bolsista PIBIC/CNPq. E-mail: evandrojost@bol.com.br

( $\left.{ }^{4}\right)$ Fundação Estadual de Pesquisa Agropecuária (FEPAGRO). Rua Gonçalves Dias, 570, Bairro Menino Deus, 90130-060 Porto Alegre (RS). E-mail: alberto-cargnelutti@fepagro.rs.gov.br 


\section{INTRODUÇÃO}

O feijoeiro comum (Phaseolus vulgaris L.) apresenta grande variedade de cores de grãos, dos mais distintos grupos comerciais, disponíveis para cultivo. Embora exista preferência regional por determinada coloração do tegumento dos grãos, feijões do grupo carioca são os mais cultivados no Brasil (YокоYAMA et al., 1996). Desse grupo, a cultivar Carioca é a preferida e, por isso, as novas cultivares deverão ter características de grãos semelhantes a essa para aumentar a probabilidade de aceitação por produtores e consumidores (ABREU et al., 1994).

Assim, as exigências do mercado consumidor, muitas vezes, estabeleceram as prioridades dos programas de melhoramento genético. Atualmente, para o feijão, as características de grãos que mais merecem atenção são o tamanho, o formato e sobretudo a coloração do tegumento (TEIXEIRA et al., 2001). Acredita-se que cinco genes com interação complexa controlam a cor do grão em feijão (BRADY et al., 1998).

O ciclo também é uma característica importante, pois as variações encontradas possibilitam o melhor planejamento da época de semeadura e da utilização racional do campo de produção agrícola. As cultivares de feijoeiro comum disponíveis para cultivo no Brasil apresentam diferenças genéticas quanto ao início do florescimento e ao ciclo, sendo o último considerado intermediário (aproximadamente 90 dias) para a maioria das cultivares disponíveis (ZIMMERMANN et al., 1996). De acordo com esses autores, as cultivares precoces apresentam um ciclo de aproximadamente 70 dias.

O feijão, por ser uma espécie com ciclo anual e desenvolvimento precoce, é mais sensível às variações ambientais (ROSSE e VeNCOVSKY, 2000). Assim, alterações nas condições climáticas podem provocar mudanças acentuadas na produtividade; por esse motivo, a identificação de cultivares com adaptação ampla é desejável (RAMALHo et al., 1993), e inúmeros trabalhos de avaliação de adaptação e de estabilidade foram realizados considerando-se unicamente o rendimento de grãos.

Recentemente, tem-se observado efeitos significativos da interação genótipo $\mathrm{x}$ ambiente em características tecnológicas e culinárias do feijoeiro (Scholz e FonseCa JúnIOR, 1999a,b). Acredita-se que as condições do grão, no momento da colheita (seca ou chuva), interferem na qualidade fisiológica dos grãos com modificações nas características do tegumento (integridade), o que influencia na absorção de água e no tempo de cozimento (CARBonell et al., 2003).
No entanto, não se tem conhecimento de que investigações tenham sido feitas para a coloração do tegumento dos grãos e para o ciclo.

Diante desses fatos, torna-se importante o conhecimento do comportamento (adaptabilidade e estabilidade) das cultivares de feijão frente às variações ambientais entre e dentro de anos (safra e safrinha) para coloração do tegumento dos grãos e para ciclo, o que é pouco conhecido. Essas informações tornam-se indispensáveis, pois é comum a utilização de duas épocas tradicionais de semeadura de feijão na Região Sul do País: a safra (setembro a outubro) e a safrinha (janeiro a fevereiro). Assim, o objetivo deste trabalho foi o de estudar a interação genótipo x ambiente, visando à identificação de cultivares com estabilidade para a coloração do tegumento dos grãos e para o ciclo na região da Depressão Central do Rio Grande do Sul, com a finalidade de orientar as novas propostas para pesquisa em melhoramento genético do feijoeiro comum.

\section{MATERIAL E MÉTODOS}

Seis experimentos foram desenvolvidos nos anos agrícolas de 2000/01, 2001/02 e 2002/03, nos cultivos de safra (semeadura em setembro-outubro) e de safrinha (semeadura em janeiro-fevereiro), no Campus da Universidade Federal de Santa Maria. A cidade de Santa Maria está localizada entre as coordenadas geográficas de $29^{\circ} 45^{\prime}$ de latitude sul, $53^{\circ} 42^{\prime}$ de longitude a oeste de Greenwich, e a uma altitude de $95 \mathrm{~m}$, na região fisiográfica da Depressão Central do Rio Grande do Sul.

O delineamento experimental utilizado foi o de blocos casualizados, com três repetições, e os tratamentos avaliados constituíram-se de 16 cultivares de feijão. A unidade experimental foi composta por quatro fileiras de $4 \mathrm{~m}$ de comprimento, espaçadas em $0,5 \mathrm{~m}$, e com área útil de $3 \mathrm{~m}^{2}$ (foram consideradas apenas as duas fileiras centrais, desprezando-se 0,5 $\mathrm{m}$ nas extremidades). A densidade de semeadura foi ajustada de acordo com o hábito de crescimento de cada cultivar (CEPEF, 2001).

O solo do local é classificado como Alissolo Hipocrômico argilúvico típico, pertencente à unidade de mapeamento Santa Maria, e foi preparado de forma convencional. As adubações foram baseadas na análise química do solo e os tratos culturais - controle de insetos e de plantas invasoras - foram realizados sempre que necessário, a fim de não comprometer o desenvolvimento da cultura. 
A coloração do tegumento dos grãos foi avaliada logo após a colheita, com umidade aproximada de $12 \%$, com colorímetro. Utilizou-se o sistema L-a-b: o eixo vertical ' $L$ ' avalia a claridade da cor do tegumento, variando do preto ao branco, o eixo ' $\mathbf{a}$ ' do verde ao vermelho e o eixo ' $\mathbf{b}$ ' do azul ao amarelo. Considerando que a claridade do tegumento dos grãos é importante para feijão, foram apresentados somente os valores de ' $L$ '. Para a avaliação de ciclo, considerou-se o número de dias transcorridos da emergência à maturação de $50 \%+1$ das plantas da parcela.

Os dados obtidos foram submetidos à análise de variância individual e conjunta, e o efeito de cultivar foi considerado fixo, enquanto os efeitos de ambiente e de bloco foram considerados aleatórios. A análise de adaptabilidade e de estabilidade foram realizadas segundo o modelo de Eberhart e Russell (1966).

As análises estatísticas foram efetuadas com o auxílio do programa GENES (CRUZ, 2001).

\section{RESULTADOS E DISCUSSÃO}

As análises de variância individuais revelaram que o índice entre o maior e o menor quadrado médio do erro dos ambientes em relação à coloração do tegumento dos grãos $(5,55)$ e ao ciclo
$(7,09)$ foi, respectivamente, inferior e levemente superior ao valor 7, sugerido por Pimentel Gomes (1990), indicando homogeneidade das variâncias residuais entre os ambientes, o que possibilita a realização da análise conjunta. A significância da interação cultivar $x$ ambiente foi detectada em relação à coloração do tegumento dos grãos e ao ciclo, evidenciando resposta diferenciada das cultivares de feijão aos ambientes avaliados (anos e épocas de cultivo) (Tabela 1). Resultado semelhante tem sido relatado na literatura para rendimento de grãos em feijão, cujos efeitos cultivares $x$ anos e cultivares $x$ épocas de semeadura são significativos (RAMALHO et al., 1998; Cormbra et al., 1999; Elias et al., 1999; PianA et al., 1999; Ribeiro et al., 2003a).

Os coeficientes de variação ambiental obtidos são considerados baixos (Tabela 1), o que confere alta precisão experimental para as estimativas obtidas (Lúcio, 1997).

$\mathrm{O}$ índice $\mathrm{B}$, que corresponde à relação entre o coeficiente de variação da variabilidade genética $(\mathrm{CVg})$ e o coeficiente de variação ambiental (CVe), revela que a variabilidade genética entre as cultivares estudadas é maior para a coloração do tegumento dos grãos do que a observada para ciclo. Portanto, a coloração do tegumento dos grãos, medida pela claridade da amostra (valor de L) pode ser mais eficiente para a diferenciação entre genótipos de feijão.

Tabela 1. Resumo da análise de variância conjunta da coloração do tegumento dos grãos (valor L) e do número de dias da emergência à colheita, de 16 cultivares de feijão, avaliadas em seis ambientes. Santa Maria (RS), UFSM, 2003

\begin{tabular}{lccc}
\hline \multirow{2}{*}{ Causas da variação } & Graus de liberdade & \multicolumn{2}{c}{ Quadrado médio } \\
\cline { 3 - 4 } & & Coloração (L) & Ciclo (dias) \\
\hline Blocos/ambiente & 12 & 2,3480 & 48,4861 \\
Cultivares (C) & 15 & $5122,4276^{*}$ & $133,9016^{*}$ \\
Ambientes (A) & 5 & $174,4056^{*}$ & $396,6035^{*}$ \\
Interação C x A & 75 & $9,9725^{*}$ & $19,9161^{*}$ \\
Resíduo & 180 & 0,5417 & 2,4824 \\
\hline Média & & 33,96 & 77,48 \\
CVg (\%) & & 49,63 & 3,25 \\
CVe (\%) & & 2,17 & 2,03 \\
Índice B (CVg/CVe) & 22,90 & 1,60 \\
h $^{2}(\%)$ & & 99,81 & 85,13 \\
\hline
\end{tabular}

* Significativo a $5 \%$ de probabilidade de erro pelo teste F. CVg $(\%)=$ coeficiente de variação da variabilidade genética. CVe (\%) = coeficiente de variação ambiental. Î́ndice $\mathrm{B}=$ relação $\mathrm{CVg} /$ Cve. $\mathrm{h}^{2}$ = coeficiente de determinação genotípico. 
O coeficiente de determinação genotípico obtido foi alto para as características estudadas, principalmente para a coloração do tegumento dos grãos $(99,81 \%)$, sugerindo facilidades para a seleção dessa característica, o que era esperado, por ser um caractere qualitativo.

Índices ambientais positivos foram obtidos nos anos agrícolas de 2000/01 e de 2001/02, nos cultivos de safra e de safrinha, caracterizando ambientes favoráveis (maiores valores de L) para a coloração do tegumento dos grãos de feijão (Tabela 2). Entretanto, no ano agrícola de 2002/03, índices ambientais negativos foram observados, o que representa ambientes desfavoráveis (menores valores de L). Acredita-se que a alta incidência de precipitação pluvial observada durante o subperíodo floração, a maturação fisiológica nos cultivos de safra e de safrinha tenha sido a causa dos menores valores de L obtidos em 2002/03.

O excesso de umidade, principalmente durante o período de enchimento de grãos, contribuiu para o maior escurecimento do tegumento dos grãos nas cultivares de cor clara (menores valores de $\mathrm{L}$ ).

Tabela 2. Coloração do tegumento dos grãos (valor L), de 16 cultivares de feijão, avaliadas em seis ambientes, média geral, coeficiente de variação em porcentagem (CV), quadrado médio do erro (QMe) e índice ambiental (IA). Santa Maria (RS), UFSM, 2003

\begin{tabular}{|c|c|c|c|c|c|c|c|c|c|}
\hline \multirow{2}{*}{ Cultivar } & \multicolumn{2}{|c|}{$2000 / 01$} & \multicolumn{2}{|c|}{$2001 / 02$} & \multicolumn{4}{|c|}{$2002 / 03$} & \multirow{2}{*}{ Média } \\
\hline & Safra & Safrinha & Safra & Safrinha & \multicolumn{2}{|c|}{ Safra } & \multicolumn{2}{|c|}{ Safrinha } & \\
\hline \multicolumn{10}{|c|}{ Grupo comercial carioca } \\
\hline Carioca & 56,56 bc & $57,07 \mathrm{~cd}$ & $56,93 \mathrm{ab}$ & $55,14 \quad c$ & 51,60 & $\mathrm{a}$ & 51,91 & $\mathrm{ab}$ & 54,87 \\
\hline Iapar 31 & $54,19 \mathrm{~d}$ & 54,92 e & $55,76 \mathrm{~b}$ & 55,56 bc & 52,42 & $\mathrm{a}$ & 46,25 & c & 53,18 \\
\hline Pérola & $54,98 \mathrm{~cd}$ & 55,56 de & 58,07 a & 56,89 abc & 48,65 & $\mathrm{~b}$ & 53,61 & a & 54,63 \\
\hline TPS Bonito & 61,55 a & $60,01 \mathrm{ab}$ & 57,95 a & $57,21 \mathrm{ab}$ & 50,91 & $\mathrm{a}$ & 53,19 & a & 56,80 \\
\hline \multicolumn{10}{|c|}{ Grupo comercial manteigão } \\
\hline Iraí & $58,37 \mathrm{~b}$ & 60,47 a & 58,95 a & 58,53 a & 51,14 & $\mathrm{a}$ & 52,22 & a & 56,61 \\
\hline PR 468 & $56,11 \mathrm{~cd}$ & 57,97 bc & 58,67 a & 55,38 bc & 45,89 & c & 49,98 & $\mathrm{~b}$ & 54,00 \\
\hline \multicolumn{10}{|c|}{ Grupo comercial preto } \\
\hline Diamante Negro & 22,13 e & $22,69 \mathrm{fg}$ & $21,47 \mathrm{c}$ & 21,63 e & 20,12 & $d$ & 20,15 & e & 21,37 \\
\hline Guapo Brilhante & 22,73 e & $23,45 \mathrm{fg}$ & $21,10 \mathrm{c}$ & 19,75 e & 19,77 & $\mathrm{~d}$ & 19,27 & e & 21,01 \\
\hline Guateian 6662 & $22,30 \mathrm{e}$ & $21,42 \mathrm{~g}$ & $21,16 \mathrm{c}$ & 21,01 e & 20,61 & $\mathrm{~d}$ & 19,35 & e & 20,98 \\
\hline Iapar 44 & $22,20 \mathrm{e}$ & $21,74 \mathrm{fg}$ & $21,15 \mathrm{c}$ & $24,69 \mathrm{~d}$ & 20,90 & $\mathrm{~d}$ & 19,65 & e & 21,72 \\
\hline Macanudo & 23,85 e & $22,12 \mathrm{fg}$ & $22,51 \mathrm{c}$ & 21,04 e & 20,03 & $\mathrm{~d}$ & 23,12 & $\mathrm{~d}$ & 22,11 \\
\hline Macotaço & $22,81 \mathrm{e}$ & $23,70 \mathrm{f}$ & $22,07 \mathrm{c}$ & 21,14 e & 19,46 & $\mathrm{~d}$ & 19,45 & e & 21,44 \\
\hline Minuano & 23,04 e & $22,99 \mathrm{fg}$ & 20,89 c & 20,50 e & 19,61 & $\mathrm{~d}$ & 23,91 & $\mathrm{~d}$ & 21,82 \\
\hline Rio Tibagi & $22,94 \mathrm{e}$ & $22,26 \mathrm{fg}$ & $21,41 \mathrm{c}$ & 20,43 e & 19,50 & $\mathrm{~d}$ & 19,49 & e & 21,01 \\
\hline TPS Bionobre & $22,23 \mathrm{e}$ & $22,79 \mathrm{fg}$ & $21,34 \quad \mathrm{c}$ & 20,49 e & 19,90 & $\mathrm{~d}$ & 19,68 & e & 21,07 \\
\hline TPS Nobre & $22,44 \mathrm{e}$ & $21,46 \mathrm{~g}$ & $20,94 \mathrm{c}$ & $20,51 \mathrm{e}$ & 19,55 & $\mathrm{~d}$ & 19,41 & e & 20,72 \\
\hline Média & 35,53 & 35,66 & 35,02 & 34,37 & 31,25 & & 31,92 & & 33,96 \\
\hline $\mathrm{CV}(\%)$ & 1,58 & 1,20 & 2,41 & 2,12 & 2,22 & & 3,17 & & 2,17 \\
\hline Qme & 0,3160 & 0,1842 & 0,7154 & 0,5331 & 0,479 & & 1,021 & & 0,5417 \\
\hline IA & 1,57 & 1,71 & 1,07 & 0,41 & $-2,71$ & & $-2,04$ & & - \\
\hline
\end{tabular}

Médias dos tratamentos seguidas de letras diferentes na coluna diferem entre si a 5\% de probabilidade de erro pelo teste de Tukey. 
Em feijões do grupo carioca, a coloração clara do tegumento dos grãos é desejável, pois existe uma associação com as características de feijão recémcolhido. Para tanto, os programas de melhoramento têm priorizado o desenvolvimento de cultivares com claridade semelhante à Carioca, que serve de padrão (testemunha) (CARNEIRO et al., 2000). Em vista da coloração clara do tegumento e também pelo padrão de grão, a 'Carioca' tem sido extensivamente utilizada como genitora em diversos cruzamentos controlados para aumentar a probabilidade de obtenção de germoplasma com valor de L superior a 53 , ou seja, com maior claridade dos grãos que deverá ser mantida, independentemente das condições ambientais no momento da colheita dos grãos.

Ao que tudo indica, cultivos realizados em épocas mais chuvosas favorecem a obtenção de grãos com menor claridade, não desejável em feijão carioca. Assim, atenção especial deve ser dada no descarte de linhagens consideradas fora do padrão de cor, para esse grupo comercial, sob o risco de não se estar considerando a influência ambiental sobre essa característica.
Já em feijões do grupo comercial preto, quanto menor o valor de $\mathrm{L}$, mais escuro será o grão, e valores de L dentro da faixa de 20 a 22 podem ser considerados adequados (Ribeiro et al., 2003b). A maior claridade, nesse caso, deprecia o valor comercial pela presença de grãos arroxeados, sendo importante que os valores de L sejam mantidos dentro da faixa considerada ideal. Nesse caso, as influências ambientais manifestadas pelos anos e épocas de cultivo não provocaram alterações substanciais na coloração do tegumento dos grãos, o que sugere que a seleção com a utilização do valor de L poderá ser eficiente em qualquer ambiente para feijões do grupo comercial preto.

A cultivar Macotaço, que apresentou coeficiente de regressão estatisticamente igual à unidade e desvios da regressão não significativo e elevado coeficiente de determinação $\left(R^{2}\right)$, pode ser considerada de ampla adaptabilidade para a coloração do tegumento dos grãos na região da Depressão Central do Rio Grande do Sul (Tabela 3).

Tabela 3. Estimativas dos parâmetros de adaptabilidade e de estabilidade fenotípica da coloração do tegumento dos grãos (valor L), de 16 cultivares de feijão, avaliadas em seis ambientes, segundo o método de EBERHART e RUSSELL (1966). Santa Maria (RS), UFSM, 2003

\begin{tabular}{|c|c|c|c|c|}
\hline Cultivar & Média do valor $L\left(\hat{\beta}_{0 \mathrm{i}}\right)$ & Coeficiente de regressão $\hat{\bigotimes}_{1 \mathrm{i}}$ ) & Desvio de regressão $\left(\hat{\sigma}_{\mathrm{di}}^{2}\right)$ & $\mathrm{R}_{\mathrm{i}}^{2}(\%)$ \\
\hline \multicolumn{5}{|c|}{ Grupo comercial carioca } \\
\hline Carioca & 54,87 & $1,30^{*}$ & $0,02 \mathrm{~ns}$ & 97,45 \\
\hline Iapar 31 & 53,18 & $1,35^{*}$ & $7,80^{*}$ & 50,86 \\
\hline Pérola & 54,63 & $1,38^{*}$ & $4,91^{*}$ & 62,85 \\
\hline TPS Bonito & 56,80 & $2,07^{*}$ & $0,85^{*}$ & 94,98 \\
\hline \multicolumn{5}{|c|}{ Grupo comercial manteigão } \\
\hline Iraí & 56,61 & $2,00^{*}$ & $0,69^{*}$ & 95,45 \\
\hline PR 468 & 54,00 & $2,52^{*}$ & $2,45^{*}$ & 91,64 \\
\hline \multicolumn{5}{|c|}{ Grupo comercial preto } \\
\hline Diamante Negro & 21,37 & $0,53^{*}$ & $-0,07 \mathrm{~ns}$ & 91,82 \\
\hline Guapo Brilhante & 21,01 & $0,74^{*}$ & $1,14^{*}$ & 65,09 \\
\hline Guateian 6662 & 20,98 & $0,40^{*}$ & $0,27^{*}$ & 62,37 \\
\hline Iapar 44 & 21,72 & $0,43^{*}$ & $2,55^{*}$ & 23,72 \\
\hline Macanudo & 22,11 & $0,35^{*}$ & $1,70^{*}$ & 22,47 \\
\hline Macotaço & 21,44 & $0,88 \mathrm{~ns}$ & $0,15 \mathrm{~ns}$ & 91,51 \\
\hline Minuano & 21,82 & $0,22^{*}$ & $3,28^{*}$ & 6,20 \\
\hline Rio Tibagi & 21,01 & $0,69^{*}$ & $0,25 \mathrm{~ns}$ & 83,39 \\
\hline TPS Bionobre & 21,07 & $0,60^{*}$ & $0,22 \mathrm{~ns}$ & 80,26 \\
\hline TPS Nobre & 20,72 & $0,55^{*}$ & $0,13 \mathrm{~ns}$ & 81,65 \\
\hline
\end{tabular}

Ho $=\hat{\beta}_{1 \mathrm{i}}=1 *$ significativo a $5 \%$ de probabilidade pelo teste $\mathrm{t}$; ns: não significativo.

Ho $=\hat{\sigma}_{\mathrm{di}}^{2}=0 *$ significativo a $5 \%$ de probabilidade pelo teste $\mathrm{F} ;$ ns: não significativo. 
As cultivares - Carioca, Diamante Negro, TPS Nobre, Macotaço, Rio Tibagi e TPS Bionobre apresentaram desvio de regressão próximo a zero, caracterizando alta estabilidade, ou seja, previsibilidade de comportamento para a coloração do tegumento dos grãos. Nenhuma cultivar do grupo carioca apresentou valores de L superiores a $53 \mathrm{em}$ todos os ambientes testados.

No grupo preto, as cultivares Diamante Negro, TPS Nobre e TPS Bionobre são desejáveis por manterem baixos valores de $\mathrm{L}$ nos diferentes ambientes. Por sua vez, 'Rio Tibagi', apesar de apresentar padrão de cor satisfatório, apresenta restrições para a comercialização dos grãos por serem de pequeno peso e soltarem a casca após o cozimento.

Já a Macotaço, que segundo os critérios de EBERHART e Russel (1966) é desejável por possuir adaptabilidade e estabilidade de comportamento, poderá apresentar restrições pelo mercado consumidor devido à presença de grãos arroxeados, o que é associado com feijão armazenado em condições inadequadas e por longos períodos.

Com relação ao ciclo, observou-se que índices ambientais negativos caracterizaram ambientes que propiciaram a obtenção de genótipos com maior precocidade (Tabela 4). Ao que tudo indica, é necessário maior período de tempo para as plantas atingirem a maturação fisiológica nos cultivos realizados em épocas mais chuvosas e, como conseqüência, o ciclo fica mais longo e há o escurecimento do tegumento dos grãos, como já relatado.

A maioria das cultivares avaliadas apresentou adaptabilidade para ciclo na região da Depressão Central do Rio Grande do Sul (Tabela 5).

A 'Guapo Brilhante' e, coincidentemente as cultivares PR 468, TPS Bionobre e TPS Bonito, registradas para cultivo mais recentemente no Estado, não apresentaram coeficiente de regressão estatisticamente igual à unidade, ou seja, não possuem ampla adaptabilidade para ciclo.

Tabela 4. Número de dias da emergência à colheita, de 16 cultivares de feijão, avaliadas em seis ambientes, média geral, coeficiente de variação em percentagem (CV), quadrado médio do erro (QMe) e índice ambiental (IA). Santa Maria (RS), UFSM, 2003

\begin{tabular}{|c|c|c|c|c|c|c|c|}
\hline \multirow{2}{*}{ Cultivar } & \multicolumn{2}{|c|}{$2000 / 01$} & \multicolumn{2}{|c|}{$2001 / 02$} & \multicolumn{2}{|c|}{$2002 / 03$} & \multirow[t]{2}{*}{ Média } \\
\hline & Safra & Safrinha & Safra & Safrinha & Safra & Safrinha & \\
\hline \multicolumn{8}{|c|}{ Grupo comercial carioca } \\
\hline Carioca & $80,00 \mathrm{bc}$ & $78,00 \mathrm{a}$ & $74,67 \mathrm{ab}$ & 81,33 bc & $80,00 \mathrm{abc}$ & $81,33 \mathrm{ab}$ & 79,22 \\
\hline Iapar 31 & $80,00 \mathrm{bc}$ & $77,67 \mathrm{ab}$ & 74,00 abc & $85,33 \mathrm{ab}$ & 81,33 abc & 81,67 ab & 80,00 \\
\hline Pérola & $82,67 \mathrm{ab}$ & 78,00 a & 77,33 a & 86,00 a & 83,67 a & 84,00 a & 81,94 \\
\hline TPS Bonito & 85,00 a & $76,67 \mathrm{abc}$ & $73,67 \mathrm{abc}$ & 76,00 de & 77,33 cde & 80,67 ab & 78,22 \\
\hline \multicolumn{8}{|c|}{ Grupo comercial manteigão } \\
\hline Iraí & $67,00 \mathrm{f}$ & $72,00 \mathrm{~d}$ & $70,00 \mathrm{c}$ & $74,00 \mathrm{e}$ & $67,67 \mathrm{~g}$ & $78,67 \quad b$ & 71,56 \\
\hline PR 468 & $67,00 \mathrm{f}$ & $72,33 \mathrm{~cd}$ & $70,00 \mathrm{c}$ & 81,33 bc & $70,33 \mathrm{fg}$ & $79,00 \quad b$ & 73,33 \\
\hline \multicolumn{8}{|c|}{ Grupo comercial preto } \\
\hline Diamante Negro & $80,00 \mathrm{bc}$ & $77,67 \mathrm{ab}$ & $75,33 \mathrm{ab}$ & 87,00 a & 83,67 a & $82,33 \mathrm{ab}$ & 81,00 \\
\hline Guapo Brilhante & $72,67 \mathrm{de}$ & 73,33 bcd & $71,67 \mathrm{bc}$ & 76,33 de & 77,33 cde & $82,67 \mathrm{ab}$ & 75,67 \\
\hline Guateian 6662 & $77,00 \mathrm{~cd}$ & 78,33 a & 74,00 abc & 76,00 de & $78,67 \mathrm{bcd}$ & $82,67 \mathrm{ab}$ & 77,78 \\
\hline Iapar 44 & $80,00 \mathrm{bc}$ & 78,33 a & $75,33 \mathrm{ab}$ & $79,00 \mathrm{~cd}$ & $82,00 \mathrm{ab}$ & 84,00 a & 79,78 \\
\hline Macanudo & $72,00 \mathrm{e}$ & $77,00 \mathrm{ab}$ & 71,33 bc & 76,33 de & 75,00 de & $80,67 \mathrm{ab}$ & 75,39 \\
\hline Macotaço & $72,00 \mathrm{e}$ & 75,67 abcd & $73,00 \mathrm{abc}$ & 76,00 de & $82,00 \mathrm{ab}$ & $83,00 \mathrm{ab}$ & 76,94 \\
\hline Minuano & $78,00 \mathrm{c}$ & $77,33 \mathrm{ab}$ & $72,67 \mathrm{bc}$ & 76,00 de & 74,00 ef & 81,00 ab & 76,50 \\
\hline Rio Tibagi & $78,67 \mathrm{bc}$ & $77,00 \mathrm{ab}$ & $75,67 \mathrm{ab}$ & 76,00 de & $79,00 \mathrm{bcd}$ & $83,00 \quad a b$ & 78,22 \\
\hline TPS Bionobre & $72,00 \mathrm{e}$ & $77,00 \mathrm{ab}$ & $71,33 \mathrm{bc}$ & 76,00 de & 77,67 bcde & $82,67 \quad a b$ & 76,11 \\
\hline TPS Nobre & $78,00 \mathrm{c}$ & $77,00 \mathrm{ab}$ & $73,33 a b c$ & 76,00 de & 80,00 abc & $84,00 \quad$ a & 78,06 \\
\hline Média & 76,38 & 76,46 & 73,33 & 78,67 & 78,10 & 81,96 & 77,48 \\
\hline CV (\%) & 1,86 & 1,09 & 2,74 & 2,81 & 1,53 & 1,65 & 2,03 \\
\hline Qme & 2,0208 & 0,6903 & 4,0389 & 4,8931 & 1,4236 & 1,8278 & 2,4824 \\
\hline $\mathrm{IA}$ & $-1,11$ & $-1,02$ & $-4,15$ & 1,18 & 0,62 & 4,48 & - \\
\hline
\end{tabular}

Médias dos tratamentos seguidas de letras diferentes na coluna diferem entre si a $5 \%$ de probabilidade de erro pelo teste de Tukey. 
Todas as cultivares avaliadas de feijão apresentaram desvio de regressão significativo, caracterizando baixa estabilidade, ou seja, manifestaram baixa previsibilidade de comportamento para ciclo, o que sugere que essa variável é muito influenciada pelo ambiente.

A duração do ciclo em feijão é muito variável ao longo dos anos, provavelmente por ser governado por vários pares de genes, constituindo-se um caractere quantitativo (RibeIRo et al., 2004). As variações encontradas para duração de ciclo possibilitam o melhor planejamento da época de semeadura e da utilização racional do campo de produção agrícola.

Os resultados do presente estudo permitem afirmar que as cultivares Carioca, Diamante Negro, TPS Nobre e TPS Bionobre apresentaram alta previsibilidade para a obtenção de grãos de feijão com coloração de tegumento adequado às exigências do mercado consumidor. Sugere-se, assim, a utilização de 'Carioca' em cruzamentos dirigidos para a obtenção de germoplasma com maior claridade do tegumento dos grãos em feijão carioca (maior valor de L) e as cultivares Diamante Negro, TPS Nobre e TPS Bionobre poderão ser utilizadas para o desenvolvimento de germoplasma com menor claridade em feijão preto (menor valor de L). Com relação ao ciclo, nenhuma das cultivares de feijão avaliadas possui previsibilidade para o período transcorrido da emergência à colheita das plantas na região da Depressão Central do Rio Grande do Sul.

\section{CONCLUSÃO}

Com base nos resultados apresentados, e para os ambientes considerados - na região da Depressão Central do Rio Grande do Sul - as cultivares Carioca, Diamante Negro, TPS Nobre e TPS Bionobre apresentam alta previsibilidade para a obtenção de grãos de feijão com coloração de tegumento adequado às exigências do mercado consumidor. Nenhuma cultivar de feijão apresentou estabilidade para ciclo.

Tabela 5. Estimativas dos parâmetros de adaptabilidade e de estabilidade fenotípica do número de dias da emergência à colheita, de 16 cultivares de feijão, avaliadas em seis ambientes, segundo método de EBERHART e RUSSEL (1966). Santa Maria (RS), UFSM, 2003

\begin{tabular}{|c|c|c|c|c|c|}
\hline Cultivar & $\begin{array}{c}\text { Hábito de } \\
\text { crescimento** }^{* *}\end{array}$ & $\begin{array}{c}\text { Média } \\
(\text { dias })\left(\hat{\beta}_{0 \mathrm{i}}\right)\end{array}$ & $\begin{array}{c}\text { Coeficiente } \\
\text { de regressão }\left(\hat{\beta}_{1 \mathrm{i}}\right)\end{array}$ & $\begin{array}{c}\text { Desvio } \\
\text { de regressão }\left(\hat{\sigma}_{\mathrm{di}}^{2}\right)\end{array}$ & $\mathrm{R}_{\mathrm{i}}^{2}(\%)$ \\
\hline \multicolumn{6}{|c|}{ Grupo comercial carioca } \\
\hline Carioca & III & 79,22 & $0,77 \mathrm{~ns}$ & $1,17^{*}$ & 75,26 \\
\hline Iapar 31 & III & 80,00 & $1,01 \mathrm{~ns}$ & $7,17^{*}$ & 57,05 \\
\hline Pérola & III & 81,94 & $0,91 \mathrm{~ns}$ & $5,93^{*}$ & 55,66 \\
\hline TPS Bonito & III & 78,22 & $0,50^{*}$ & $16,7^{*}$ & 12,89 \\
\hline \multicolumn{6}{|c|}{ Grupo comercial manteigão } \\
\hline Iraí & I & 71,56 & $1,05 \mathrm{~ns}$ & $11,56^{*}$ & 47,86 \\
\hline PR 468 & I & 73,33 & $1,33^{*}$ & $20,31^{*}$ & 46,27 \\
\hline \multicolumn{6}{|c|}{ Grupo comercial preto } \\
\hline Diamante Negro & II & 81,00 & $1,04 \mathrm{~ns}$ & $10,38^{*}$ & 49,68 \\
\hline Guapo Brilhante & II & 75,67 & $1,34^{*}$ & $1,22^{*}$ & 90,08 \\
\hline Guateian 6662 & II & 77,78 & $0,88 \mathrm{~ns}$ & $1,96^{*}$ & 74,10 \\
\hline Iapar 44 & III & 79,78 & $0,94 \mathrm{~ns}$ & $1,27^{*}$ & 81,48 \\
\hline Macanudo & III & 75,39 & $1,05 \mathrm{~ns}$ & $2,62^{*}$ & 76,83 \\
\hline Macotaço & III & 76,94 & $1,27 \mathrm{~ns}$ & $8,82^{*}$ & 63,15 \\
\hline Minuano & III & 76,50 & $0,76 \mathrm{~ns}$ & $4,31^{*}$ & 53,72 \\
\hline Rio Tibagi & II & 78,22 & $0,74 \mathrm{~ns}$ & $2,65^{*}$ & 61,94 \\
\hline TPS Bionobre & II & 76,11 & $1,30^{*}$ & $3,24^{*}$ & 81,06 \\
\hline TPS Nobre & II & 78,06 & $1,12 \mathrm{~ns}$ & $2,99^{*}$ & 77,11 \\
\hline
\end{tabular}

$\mathrm{H}_{\mathrm{O}}=\hat{\beta}_{1 \mathrm{i}}=1 *$ significativo a $5 \%$ de probabilidade pelo teste $\mathrm{t}$; ns: não significativo. $\mathrm{H}_{\mathrm{O}}=\hat{\sigma}_{\mathrm{di}}^{2}=0$ * significativo a $5 \%$ de probabilidade pelo teste F; ns: não significativo.

** Hábito de crescimento: I = determinado; II = indeterminado com ramificações fechadas; III = indeterminado com ramificações abertas. 


\section{REFERÊNCIAS}

ABREU, A.F.B.; RAMALHO, M.A.P.;SANTOS, J.B.; MARTINS, L.A. Progresso do melhoramento genético do feijoeiro nas décadas de setenta e oitenta nas regiões Sul e Alto Paranaíba em Minas Gerais. Pesquisa Agropecuária Brasileira, Brasília, v.29, n.1, p.105-112, 1994.

BRADY, L.; BASSETT, M.J.; McCLEAN, P.E. Molecular markers associated with $\mathrm{T}$ and $\mathrm{Z}$, two genes controlling partly colored seed coat patterns in common bean. Crop Science, Madison, v.38, n.4, p.1073-1075, 1998.

CARBONELL, S. A. M.; CARVALHO, C. R. L.; PEREIRA, V. R. Qualidade tecnológica de grãos de genótipos de feijoeiro cultivados em diferentes ambientes. Bragantia, Campinas, v.62, n.3, p.369-379, 2003.

CARNEIRO, G.E.S.; SOARES, D.M.; COSTA, J.G.C. Resultados do ensaio Sul-Brasileiro de avaliação de linhagens de feijão nos anos 1997/98 e 1998/99. Santo Antônio de Goiás: Embrapa Arroz e Feijão, 2000. 77 p. (Embrapa Arroz e Feijão. Documentos, 102).

CEPEF - COMISSÃO ESTADUAL DE PESQUISA DE FEIJÃO. Feijão: recomendações técnicas para o cultivo de feijão no Rio Grande do Sul. Erechim: São Cristovão, 2001. 112p.

COIMBRA, J.L.M.; GUIDOLIN, A.F.; CARVALHO, F.I.F.; COIMBRA, S.M.M.; HEMP, S. Reflexos da interação genótipo $x$ ambiente e suas implicações nos ganhos de seleção em genótipos de feijão (Phaseolus vulgaris L.). Ciência Rural, Santa Maria, v.29, n.3, p.433-439, 1999.

CRUZ, C.D. Programa GENES - versão Windows: aplicativo computacional em genética e estatística. Viçosa: UFV, 2001. 648p.

EBERHART, S.A.; RUSSELL, W.A. Stability parameters for comparing varieties. Crop Science, Madison, v.6, n.1, p.36-40, 1966.

ELIAS, H.T.; HEMP, S.; CANTON, T. Análise da interação genótipo $x$ ambiente na avaliação de cultivares de feijão em Santa Catarina. Pesquisa Agropecuária Gaúcha, Porto Alegre, v.5, n.2, p.271-275, 1999.

LÚCIO, A.D. Parâmetros da precisão experimental das principais culturas anuais do Estado do Rio Grande do Sul. 1997. 64f. Dissertação (Mestrado em Agronomia) Universidade Federal de Santa Maria (RS).

PIANA, C.F.B.; ANTUNES, I.F.; SILVA, J.G.C.; SILVEIRA, E.P. Adaptabilidade e estabilidade do rendimento de grãos de genótipos de feijão. Pesquisa Agropecuária Brasileira, Brasília, v.34, n.4, p.553-564, 1999.

PIMENTEL GOMES, F. Curso de estatística experimental. 13.ed. Piracicaba: Nobel, 1990. 467p.

RAMALHO, M.A.; SANTOS, J.B.; ZIMMERMANN, M.J.O. Genética quantitativa em plantas autógamas: aplicações ao melhoramento do feijoeiro. Goiânia: UFG, 1993. 271 p.
RAMALHO, M.A.P.; ABREU, A.F.B.; SANTOS, P.S.J. Interação genótipos $x$ épocas de semeadura, anos e locais na avaliação de cultivares de feijão nas regiões sul e Alto Paranaíba em Minas Gerais. Ciência e Agrotecnologia, Lavras, v.22, n.2, p.176-181, 1998.

RIBEIRO, N.D.; HOFFMANN JÚNIOR, L.; STROSCHEIN, M.R.D.; POSSEBON, S.B. Genotype $x$ environment interaction in common bean yield and yield components. Crop Breeding and Applied Biotechnology, Maringá, v.3, n.1, p.27-34, 2003a.

RIBEIRO, N.D.; POSSEBON, S.B.; STORCK, L. Progresso genético em caracteres agronômicos no melhoramento do feijoeiro. Ciência Rural, Santa Maria, v.33, n.4, p.629-633, 2003b.

RIBEIRO, N.D.; HOFFMANN JÚNIOR, L; POSSEBON, S.B. Variabilidade genética para ciclo em feijão dos grupos preto e carioca. Revista Brasileira de Agrociência, Pelotas, v.10, n.1, 2004.

ROSSE, L.N.; VENCOVSKY, R. Modelo de regressão não-linear aplicado ao estudo da estabilidade fenotípica de genótipos de feijão no Estado do Paraná. Bragantia, Campinas, v.59, n.1, p.99-107, 2000

SCHOLZ, M.B.S.; FONSECA JÚNIOR, N.S. Efeito de ambientes, dos genótipos e da interação genótipos $\mathrm{x}$ ambientes na qualidade tecnológica de feijão do grupo de cores no Estado do Paraná. In: REUNIÃO NACIONAL DE PESQUISA DO FEIJÃO, VI, 1999, Goiânia, GO. Anais... Goiânia: EMBRAPA, 1999a. 880p. p.339-342.

SCHOLZ, M.B.S.; FONSECA JÚNIOR, N.S. Influência ambiental, genotípica e sua interação na qualidade tecnológica de feijão do grupo preto no Paraná. In: REUNIÃO NACIONAL DE PESQUISA DO FEIJÃO, VI, 1999, Goiânia, GO. Anais... Goiânia: EMBRAPA, 1999b. 880p. p.389-392.

TEIXEIRA, F.F.; BALDONI, A.B.; SANTOS, J.B. Controle genético de características associadas à coloração do grão do feijão no cruzamento Rosinha x Esal 693. In: CONGRESSO BRASILEIRO DE MELHORAMENTO DE PLANTAS, 1, 2001, Goiânia. Anais... Goiânia: Sociedade Brasileira de Melhoramento de Plantas, 2001. CD-ROM.

YOKOYAMA, L.P.; BANNO, K.; KLUTHCOUSKI, J. Aspectos socioeconômicos da cultura. In: ARAUJO, S.R. et al. (Ed.). Cultura do feijoeiro comum no Brasil. Piracicaba: POTAFÓS, 1996. p. 1-21.

ZIMMERMANN, M.J.O.; CARNEIRO, J.E.S.; PELOSO, M.J.D.; COSTA, J.G.C.; RAVA, C.A.; SARTORATO, A.; PEREIRA, P.A.A. Melhoramento genético e cultivares. In: ARAUJO, S.R. et al. (Eds.). Cultura do feijoeiro comum no Brasil. Piracicaba: POTAFÓS, 1996. p.223-273. 